\title{
Concepções de professores de São Luís e de Coimbra em planejamento de aulas de Física
}

\author{
Conceptions of teachers of São Luís and Coimbra \\ in planning Physics classes
}

\author{
Maria Consuelo Alves Lima ${ }^{1}$ • https://orcid.org/0000-0002-2514-9069 \\ Raysa Myrelle Soares Lima ${ }^{1}$. https://orcid.org/0000-0003-3479-4702 \\ Maria Helena Damião ${ }^{2}$ • https://orcid.org/0000-0002-3324-4074
}

\begin{abstract}
Resumo: Este texto traz um estudo exploratório sobre concepções de práticas docentes no ensino de Física de professores brasileiros e portugueses em efetiva regência de classe, em escolas públicas da educação básica em São Luís (Maranhão, Brasil) e em Coimbra (Portugal). As concepções foram formalizadas a partir de entrevistas com esses professores e analisadas segundo noções da Análise de Discurso de origem francesa, considerando as condições desses professores para identificar aspectos que, por terem as implicações desejadas para a aprendizagem de seus alunos, consideram importantes no momento do planejamento de suas aulas. Os resultados das análises destacam que os discursos dos professores portugueses e brasileiros manifestam tendências ao uso de referenciais metodológicos de ensino, sem restrições a possibilidades de diferentes abordagens pedagógicas.
\end{abstract}

Palavras-chave: Concepções de ensino. Ensino de Física. Formação de professor. Brasil. Portugal.

\begin{abstract}
This is an exploratory study on the conceptions of teaching practices in the teaching of Physics of Brazilian and Portuguese teachers in regency of classroom, in public basic education schools in São Luís (Maranhão, Brazil) and Coimbra (Portugal). The concepts were formalized from interviews with these teachers and analyzed using notions of Discourse Analysis of French origin, considering the conditions for these teachers identify aspects they consider important when planning their lessons, assuming the desired implications for the learning of their students. The results of the analyzes point out that the speech of Portuguese and Brazilian teachers manifest tendencies to reference teaching methods without restricting the possibilities of different pedagogical approaches.
\end{abstract}

Keywords: Conceptions of teaching. Teaching of physical. Teacher education. Brazil. Portugal.

\footnotetext{
${ }^{1}$ Universidade Federal do Maranhão (UFMA), Departamento de Física, São Luís, MA, Brasil. E-mail: <mconsuelo@ufma.br>.

${ }^{2}$ Universidade de Coimbra, Faculdade de Psicologia e de Ciências da Educação, Coimbra, Portugal.
} 


\section{Introdução}

Durante séculos, o Brasil dependeu de Instituições de Ensino Superior europeias, a exemplo da Universidade de Coimbra, em Portugal, para a formação de profissionais de nível superior. Com o bloqueio continental de Napoleão e com a vinda da família real para o Brasil, a sociedade tentou, sem êxito, por mais de um século, institucionalizar a universidade neste país. Uma das primeiras tentativas foi a criação da Universidade de Manaus, em 1909, que definhou tão fugazmente quanto o seu surgimento. Somente após a proclamação da República, o Governo Federal, em 1920, utilizando instrumentos legais, criou, segundo o modelo das universidades europeias, a atual Universidade Federal do Rio de Janeiro, reconhecida como a primeira universidade brasileira. Em 1934 foram criados a Faculdade de Filosofia, Ciências e Letras e o Instituto de Educação, que, juntamente com outras Faculdades e Institutos, formaram a atual Universidade de São Paulo; e, no ano seguinte, foi criada a Universidade do Distrito Federal. Ao longo dos anos, essas e outras Instituições de Ensino Superior ganharam autonomia e, sob a orientação dos movimentos sociais, marcadamente, a revolução estudantil de 1968, as universidades brasileiras se distanciaram do modelo europeu (CAMACHO, 2005; FÁVERO, 2006). Tal distanciamento encontrou expressão reforçada entre as universidades brasileiras e portuguesas no início deste milênio, quando, ao abrigo da Declaração de Bolonha ${ }^{3}$, Portugal empreendeu uma reforma curricular no Ensino Superior, com importantes repercussões nos cursos de formação inicial de professores (DAMIÃO et al., 2009; SEIXAS et al., 2012).

$\mathrm{Na}$ atual estrutura curricular portuguesa, o modelo clássico de formação de um professor de Física é constituído de duas etapas. Inicialmente, com um ciclo de estudo de três anos, basicamente com disciplinas de vertente específica das Ciências Naturais e da Matemática, cuja conclusão confere ao estudante o certificado de Licenciado em Física, que não o habilita a lecionar. O segundo ciclo é integralizado por componentes curriculares de tratamento teórico e prático, com disciplinas de caráter pedagógico e didático, complementados por um trabalho final - uma dissertação - de investigação sobre o ensino de Física. Concluídas essas atividades, distribuídas ao longo de dois anos, é concedido ao estudante o certificado de Mestre em Ensino de Física e de Química, o qual lhe permitirá lecionar no Ensino Básico.

Diferentemente dessa estrutura de formação em dois ciclos em uma estrutura "sequencial” adotada em Portugal, no Brasil, o interessado na profissão docente deverá concluir seus estudos de formação do professor de Física em um único ciclo, com estrutura "integrada", contemplando disciplinas tanto de vertente científica quanto de formação didático-pedagógica e de caráter teórico e prático, distribuídas ao longo de quatro anos em média. É concedido ao estudante, no fim desse ciclo, o certificado de Licenciado, que o habilitará para a docência.

No contexto da educação básica em que atuam os professores da rede pública, os dois países apresentam características distintas e condições adversas, como mostram os dados oficiais das cidades em que se desenvolveu o presente estudo, São Luís (localizada no Estado do

\footnotetext{
${ }^{3}$ Declaração que criou o Espaço Europeu de Ensino Superior, assinada em 19 de junho de 1999 por Ministros da Educação de 29 países europeus.
} 
Maranhão, no Brasil) e Coimbra (em Portugal). Em São Luís, em pesquisa realizada entre abril e junho de 2010 e divulgada pela Procuradoria de Justiça Especializada na Defesa da Educação (PJEDE) de São Luís - órgão governamental responsável pela defesa dos direitos à Educação -, diagnosticou-se que as escolas estaduais apresentavam elevado número de alunos por turmas, alunos desinteressados pelas atividades escolares e despreparados para realizá-las, precariedade de medidas inclusivas, violência escolar, carga horária desajustada dos conteúdos programáticos, recursos didáticos inadequados, privação dos docentes a planos de carreira e precariedades nas condições físicas estruturais das escolas, como as condições mais preocupantes (MARANHÃO, 2010). Em Coimbra, a ausência de expectativa para ingresso na carreira docente, em curto e em médio prazos, sobretudo para os mais jovens (PORTUGAL, 2013a), e a instabilidade da carreira para os já docentes afiguram-se como dificuldades mais acentuadas. As escolas de Coimbra, na perspectiva das escolas portuguesas avaliadas pela Inspeção-Geral da Educação e Ciência (IGEC) - órgão do governo português responsável pela avaliação das escolas -, com 1.015 estabelecimentos de educação pré-escolar e dos ensinos básico e secundário, correspondentes a $22 \%$ do total dos estabelecimentos portugueses, mostram o grau de satisfação referente: ao ensino-aprendizagem; à direção e ao funcionamento; às instalações e aos serviços; e ao ambiente, à segurança e à disciplina, apontado pelo relatório de Avaliação Externa Escolar 2011-2012 (PORTUGAL, 2013b). Entre esses quatro fatores avaliados, o menor grau de satisfação é para “instalação e serviços", de acordo com as respostas de: docentes/não docentes ${ }^{4}$ (68,0\%), pais/ encarregados da educação $(64,0 \%)$ e alunos (50,2\%). Por outro lado, as respostas relativas ao fator "ambiente, segurança e disciplina" mostram ter ele o maior grau de satisfação dos três grupos consultados: docentes/não docentes $(71,1 \%)$, pais/encarregados da educação $(78,1 \%)$ e alunos (73,8\%). A satisfação dos alunos em relação a "ensino-aprendizagem" e "direção e funcionamento" corresponde, respectivamente, a 65,6\% e 53,4\%, enquanto, para os docentes / não docentes e os pais/encarregados da educação, o aspecto "ensino-aprendizagem" aponta $78,7 \%$ e 77,2 \% de satisfação, respectivamente. E, em relação a "direção e funcionamento", o índice de satisfação para esses dois grupos é de 79,0 \% e 73,5\%, respectivamente. Nos dois países, as escolas públicas se constituem no principal campo de atuação do professor da educação básica. Nesse nível de escolaridade, o ensino público brasileiro respondeu por $82,8 \%$ das matrículas no Ensino Básico no ano de 2013 (INEP, 2013), enquanto, em Portugal, no mesmo nível de escolaridade e no mesmo ano, o ensino público foi responsável por $87,8 \%$ do número de matrículas (PORDATA, 2013).

Diferenças e semelhanças entre aspectos do ensino de Física nos dois países são objetos de estudo neste trabalho, em que se destacam concepções de ensino expressas em entrevistas concedidas por professores da educação básica das cidades de São Luís e de Coimbra. As entrevistas foram concedidas à segunda autora deste trabalho durante o ano de 2013, quando participava, no período de 2011 a 2013, de um intercâmbio financiado pelo governo brasileiro, pelo Programa de Licenciaturas Internacionais (PLI), criado e financiado pela Coordenação de

\footnotetext{
${ }^{4}$ O termo "não docente" se refere a trabalhadores da escola que não são professores.
} 
Aperfeiçoamento de Pessoal de Nível Superior (Capes). O Programa, que promove intercâmbio de mobilidade de estudantes de cursos de licenciaturas oriundos de escolas públicas brasileiras, teve sua primeira edição em 2010, com a Universidade de Coimbra (Portugal). Em 2012, o Programa expandiu o intercâmbio para 11 universidades portuguesas e, a partir de 2013, foi estendido para outros países.

Partindo do princípio de que a formação dos professores e o meio escolar em que vivem exercem forte influência sobre o modo como pensam e agem, em uma "relação de sentidos estabelecida por eles em um contexto social e histórico" (ORLANDI, 2009, p. 60), buscamos, nesta investigação, compreender, a partir dos discursos dos professores brasileiros e portugueses, não apenas as concepções de ensino utilizadas por eles para tomadas de decisões no planejamento de aulas, mas também a forma como elas produzem sentidos em sua prática em aulas de Física.

\section{Referencial teórico}

As respostas dos professores durante as entrevistas foram analisadas, buscando apreender a construção discursiva de cada sujeito e o sentido de seu discurso, considerando que, "ao significar, o sujeito se significa" e que "o sentido não está já fixo a priori, como essência das palavras, tampouco pode ser qualquer um: há determinações históricas do sentido" (ORLANDI, 1994, p. 56). Os discursos foram tratados não como um meio transmissor de informações, mas como efeitos de sentido entre locutores, considerando a constituição dos sujeitos e a produção dos sentidos por eles, como entendidos pela Análise de Discurso (AD) de linha francesa.

A análise realizada se apoia principalmente em textos da linguista Eni Orlandi, alinhada com as ideias do filósofo Michel Pêcheux, precursor da AD francesa que teoriza a materialização da linguagem na ideologia e o modo como essa se manifesta na linguagem. Nesse caso, a importância do lugar da historicidade define o discurso como processo social, observando suas condições de produção e verificando como o funcionamento da memória remete o dizer a uma formação discursiva para compreender o sentido do que é dito (ORLANDI, 2005).

Partindo da ideia de que a interpretação está presente em qualquer manifestação da linguagem e que esta não faz sentido sem aquela, entende-se que a interpretação é feita em função tanto do objeto de análise como do analista. E, por isso, o analista precisa se colocar no "entremeio da descrição com a interpretação", para investigar a opacidade da linguagem e para compreender os processos de significação dos discursos, verificando os mecanismos de funcionamento desses discursos (ORLANDI, 2009).

$\mathrm{Na} A \mathrm{D}$, a relação do sujeito com suas condições de existência é mediada pela ideologia, considerando que

[...] a interpretação é sempre regida por condições de produção específicas que, no entanto, aparecem como universais, eternas. É a ideologia que produz o efeito de evidência, e da unidade, sustentando-se o já-dito, os sentidos institucionalizados, admitindo-os como naturais... A ideologia é interpretação de sentidos em certa direção, determinadas pela relação da linguagem com a história, sem seus mecanismos imaginários. Ela não é, 
pois, ocultamento, mas função necessária entre linguagem e mundo. (ORLANDI, 1994, p. 56).

A partir desse referencial, procuramos analisar como os discursos dos professores produzem sentidos; como eles podem ser lidos; e como os sentidos estão neles, considerando a materialidade da linguagem (ORLANDI, 2009).

\section{Metodologia e contexto da pesquisa}

Utilizamos um mesmo instrumento investigativo - um roteiro de entrevista no formato de perguntas semiestruturadas -, com a intenção de levar os professores a explicitar suas concepções de ensino e de aprendizagem em relação à disciplina que ministravam. Cada entrevista teve duração de uma a duas horas, e foram entrevistados oito professores de Física da educação básica da rede pública do Brasil e de Portugal: três da região de Coimbra e cinco do município de São Luís.

Os entrevistados estavam disponíveis para colaborar e em efetivo exercício em sala de aula, em escolas públicas de diferentes bairros, com diferentes índices de desenvolvimento da educação. A todos os colaboradores foi assegurada a confidencialidade das identidades, para as quais atribuímos nomes fictícios, mantendo os gêneros da identidade original.

Nas entrevistas, os professores foram levados a se imaginar planejando aulas sobre um tema de Física comum aos conteúdos curriculares oficiais brasileiros e portugueses. As entrevistas foram concedidas pelos professores portugueses durante o mês de junho de 2013, antes de a segunda autora retornar ao Brasil, após dois anos em mobilidade acadêmica na Universidade de Coimbra. No mesmo ano, ela entrevistou os professores brasileiros em sua universidade de origem, Universidade Federal do Maranhão, durante os meses de setembro e novembro.

O registro das entrevistas foi feito com papel e caneta e, posteriormente, analisado com base em noções da $\mathrm{AD}$ explicitadas anteriormente. Uma exposição sobre o objetivo do trabalho, no início de cada entrevista, oportunizou ao entrevistado questionar para que e para quem se destinava a pesquisa, e entender a possível abrangência de sua divulgação. Em seguida, o docente foi conduzido a se imaginar preparando uma aula e, com uma sequência de oito perguntas, procuramos conhecer três ações docentes: a escolha do material de apoio para a elaboração das aulas, a construção do plano de aula e a execução desse plano.

Para saber o tempo de docência e a formação profissional dos entrevistados, inicialmente cada professor foi levado a descrever sucintamente sua trajetória, do período de graduação ao exercício das atividades profissionais atuais. Os docentes portugueses revelaram que estavam em atividades na educação (quase a totalidade do tempo em sala de aula) de 16 a 21 anos, e os brasileiros, de 2 a 15 anos. A formação mínima prevista pela legislação de Portugal e do Brasil - mestre em Física e Química, e licenciado em Física, respectivamente - foi superada por seis dos oito decentes entrevistados, considerando que, dos três portugueses, um era também especialista em administração escolar e outra doutoranda; e, dos cinco brasileiros, três eram especialistas em ensino ou gestão escolar e um doutorando em Física da matéria condensada.

$\mathrm{Na}$ sequência, cada entrevistado foi conduzido a se imaginar preparando uma aula subordinada ao tema "O trabalho de uma força" e, ao se considerar nessa situação, lhe foi per- 
guntado: (1) Faria sua própria planificação ${ }^{5}$ seu próprio planejamento? Usaria a planificação/o planejamento feita/feito pela equipe docente? Usaria as planificações/orientações do livro adotado?; (2) Essa planificação/esse planejamento seria na forma escrita ou apenas mental?; (3) Usaria documento de apoio ao conhecimento científico? Se sim, quais usaria?; (4) Poderia dizer em que pensaria em primeiro lugar, ou seja, de que aspecto ou aspectos partiria?; E em seguida? E depois?; (5) Quais objetivos pretenderia alcançar com esse tema?; (6) E que metodologias usaria para tratar o tema? Qual delas desperta maior interesse nos alunos? Em qual delas os alunos aprendem mais?; (7) Em síntese, como organizaria as aulas, da primeira à última para lecionar o tema? Como as desenvolveria do começo ao fim?; (8) Agora, se o tema fosse "lei da conservação da energia", a estrutura da aula mudaria? Se sim, o que mudaria?

O foco das análises incide particularmente sobre as respostas às perguntas: "Poderia me dizer em que pensaria em primeiro lugar [no momento da construção do plano de aula/ planificação] - de que aspecto ou aspectos partiria? E em seguida? E depois? Qual a metodologia que possibilitaria maior interesse dos alunos? E qual metodologia possibilitaria maior aprendizagem? Na prática, como organizaria as aulas, da primeira à última? Como as desenvolveria do começo ao fim?".

\section{Resultados e análises}

Com entrevistas centradas na elaboração do planejamento de aulas, esperávamos, inicialmente, por respostas sobre ações de ensino que fornecessem informações de como os alunos alcançariam a aprendizagem planejada. Supomos, nesse caso, que parte do tempo do professor seja dedicada a momentos de reflexão em planejamentos, considerando o entendimento de que ele planeja "as condições para a aprendizagem de tal forma que cada um dos estudantes aprenda o que se pretende que eles saibam” (GAGNÉ, 1980, p. 4).

Ao planejar aulas, o professor traça estratégias para alcançar suas metas, que são os objetivos de aprendizagem. Uma vez que qualquer ação docente, por mais simples que seja, exige um planejamento antecipado, é útil pensá-lo como auxiliar para o controle, em longo prazo, do avanço da aprendizagem dos alunos, permitindo ao educador alcançar os melhores resultados possíveis, caso seja esse seu desejo, ao concluir as atividades docentes do período previsto.

É importante considerar também como se dará o planejamento das aulas, que, segundo Luckesi (2011, p. 210),

[...] poderá tão somente ser assumido como uma decisão e permanecer na memória viva como guia da ação. Aliás, só como memória viva ele faz sentido. Papéis e formulários são simplesmente mecanismos de registro e fixação gráfica do decidido. Não queremos dizer, com isso, que não se devam registrar as decisões do planejamento. Estamos, sim, afirmando que, em

\footnotetext{
${ }^{5}$ Termo utilizado em Portugal.
} 
primeiro lugar, o planejamento é um ato decisório político. Realizado este ato, ele pode e deve ser registrado. Só aí é que os formulários fazem sentido.

Luckesi (2011) entende que o registro das decisões, embora possa parecer uma ação simples e imediata, requer reflexões anteriores e, como resultado, poderá auxiliar o professor em suas decisões futuras. O momento do registro de um planejamento não é apenas um ato burocrático; ele é importante porque, ao escrever, o professor sistematiza suas decisões planejadas e, ao fazer esse exercício, ele torna mais claras para si suas intenções. Tendo o planejamento registrado, o professor também poderá resgatar suas ações para elaboração dos próximos planos de aula.

Observando como são executados os planejamentos de aulas dedicados ao tema investigado, os professores portugueses, sem exceção, disseram fazer registro, enquanto os professores brasileiros se dividiram: dois afirmaram fazer planejamento escrito, e os outros três fazem somente um planejamento mental.

No grupo dos brasileiros, constituído por duas professoras e três professores, as mulheres afirmaram registrar os planos de suas aulas, enquanto os homens disseram que planejam as aulas apenas mentalmente. Chama a atenção o fato de o registro escrito ser constante entre os portugueses e as professoras brasileiras. O brasileiro Cássio, ao dizer que seu plano de aula é mental, justificou que, no início da carreira, ele escrevia seus planos, mas, com o passar do tempo, foi deixando o hábito de escrever, porque passou a se sentir preparado para a aula com o plano apenas em mente. Porém, no grupo brasileiro, são os homens que têm menor tempo de docência. Analisando a justificativa de Cássio, fica claro que, para ele, o plano de aula se resume apenas à tomada de decisões para o momento imediato.

Uma possível justificativa para a ação unânime dos três professores brasileiros que fazem planejamento de aulas apenas mental, é que, para eles, o registro escrito do planejamento de aulas é somente um ato burocrático, por isso, desnecessário. Ao considerar dessa forma o planejamento de aulas, o professor se nega a utilizá-la como uma ferramenta que requer reflexões anteriores às suas ações e pode auxiliá-lo em suas decisões futuras e contribuir para elevar a qualidade do processo de ensino.

As professoras brasileiras, que disseram fazer registro escrito do plano de aula, percebem que esse planejamento as ajudará a se organizar e a refletir sobre suas ações; e que poderá ser útil na elaboração dos próximos planos de aula. Elas demonstram dedicar especial atenção ao controle de suas ações; e parecem se sentir mais preparadas para lecionar quando registram seus planos de aula e pensam em um possível retorno aos registros para, a cada planejamento, aperfeiçoar as estratégias de ensino de acordo com o perfil específico de seus alunos. No grupo de professores de Coimbra, uma professora disse que o seu plano de aula escrito, referente a cada aula, é feito em grupo com os docentes da disciplina de Física e, a partir desse plano, ela faz, além dele, um plano mental de cunho mais pessoal, a fim de adaptar o plano do grupo aos seus alunos.

Respondendo às perguntas "Poderia me dizer em que pensaria em primeiro lugar [no momento do planejamento das aulas] - de que aspecto ou aspectos partiria? E em seguida? E depois?", os professores portugueses e brasileiros apresentaram os mesmos elementos. No entanto, os dois grupos dão grau de importância diferenciado a cada elemento. Os professores de São Luís, sem exceção, apontam como interesse mais evidente levar os alunos a perceber o quanto a Física está presente no dia a dia, com a intenção de mostrar que é útil estudá-la, como revelam as falas: 


\section{Lima, M. C. A.; Lima, R. M. S.; Damião, M. H.}

Quero que primeiro eles [alunos] criem o conceito deles. Pretendo formar nos alunos bons conceitos. Tento mostrar a Física no dia a dia. A partir do próximo ano, penso em fazer aulas mais atrativas, datashow com experimentos. [Kelvin].

Prezo pela aprendizagem básica dos conteúdos. Dou muita importância a situaçoes com o dia a dia. Quando possivvel, gosto de recorrer à própria definição das palavras que compõem o assunto e assim construir o conceito físico. [Murilo].

Fico atenta para saber se eles entenderam o que é uma força. Observo se eles aprenderam os assuntos anteriores necessários para dar continuidade ao conteúdo. Pretendo que minhas aulas sejam interessantes, práticas e relacionadas com o dia a dia. Que eles percebam que têm utilidade. [Tânia].

Incentivo para que o aluno se identifique com a Física e também para pensarem na formaşão em Licenciatura em Física/Matemática/Química. Em minhas aulas, o aprendizado é voltado para o ENEM. Mostro que aquele conteúdo é aplicado no dia a dia dele [aluno]. Também mostro para que serve. Procuro trabalhar com recursos que mantêm a participação dos alunos: videoaula, laboratório. [Cássio].

Imagino coisas que introduzem a ideia do conteúdo novo. Fazer o aluno se identificar com o conteúdo e ver relação com coisas do dia a dia. [Ana].

Os professores de Coimbra mostram maior interesse em valorizar o conhecimento prévio dos alunos, para estabelecer a conexão entre esse e os conteúdos predefinidos no planejamento das aulas:

Começo com uma pergunta para tentar perceber o que os alunos sabem sobre o tema. Vou fazendo perguntas enquanto progrido com o conteúdo, sempre tentando perceber se os alunos estão entendendo. Dou atenção especial aos alunos fracos, mas que são interessados. [Sofia].

Relaciono com conbecimentos anteriores. Não faço o aluno ir ao quadro sem antes resolver a questão no próprio caderno. Dou grande importância à contextualização em situacões relacionadas com o movimento do dia a dia. Não espero que os alunos cheguem ao conceito de forma intuitiva. Deixei de lado alguns assuntos, tópicos, exemplos que não costumam aparecer em provas nacionais e os troquei por discussão de problemas das provas. [Miguel].

O que quero ensinar? Não posso me esquecer disso e daquilo. Resgatar o conbecimento dos alunos. Abordagem por imagem, exemplos, criar expectativa. [Joana].

No discurso de três professores de São Luís - Kelvin, Murilo e Tânia -, observamos interesses em estabelecer pontes entre o conhecimento prévio do aluno e o tema da aula planejada. Contudo, esse elemento não é tão destacado quanto a valorização do conhecimento da 
Física em situações do dia a dia. Entre os professores de Coimbra, há elementos comuns aos professores brasileiros, como na fala do professor Miguel, que diz ter a intenção de tornar a Física mais próxima do aluno, utilizando situações do cotidiano, embora não seja esse o elemento mais destacado nas falas dos portugueses. Independentemente do elemento enfatizado, uma constante em ambos os grupos é a importância que atribuem à percepção, pelos alunos, de utilidade no estudo da Física. Essa valorização dá a entender que os professores notam que não é desejo dos alunos estudar essa disciplina "simplesmente" pelo conhecimento que ela proporciona.

Destacamos, ainda, a preocupação com a preparação dos alunos para exames, manifestada por dois professores, um de cada país: o brasileiro Cássio, que afirma ter bem presente, no momento do planejamento, a seleção - do Exame Nacional do Ensino Médio - para ingresso no Ensino Superior; e o português Miguel, o qual afirma que, no momento de planejamento, procura se limitar aos conteúdos exigidos nos exames nacionais. Esse ensino auxilia o aluno a se familiarizar com o sistema de questões específicas desses exames e facilita seu ingresso nas Instituições de Ensino Superior, mas, por outro lado, apresenta os conteúdos da Física como uma disciplina fortemente matematizada, com exercícios que utilizam muitas fórmulas, levando "a maioria dos educandos a decorar a resolução mecânica desse tipo de exercício sem compreender os conhecimentos de Física envolvidos" (RICARDO; FREIRE, 2007, p. 254). Ao restringir o ensino aos conteúdos previstos para exames, o professor desconsidera a necessidade da formação geral do cidadão, especialmente em escola de países como Brasil e Portugal, onde a grande maioria da população tem o Ensino Médio como o último nível de escolaridade formal, e somente uma pequena parte da população alcançará o Ensino Superior (OECD, 2014).

Uma preocupação diferente com o ensino foi manifestada pelo brasileiro Kelvin, ao afirmar o desejo de que seus alunos "criem o conceito deles", indicando que os encoraja a usar as próprias palavras para explicá-los. A fala do professor revela sua intenção de levar seus alunos ao mais elevado nível da aprendizagem. No discurso desse professor, é possível identificar a noção de repetição histórica no sentido da $\mathrm{AD}$, considerando que "é impossível ao autor evitar a repetição já que sem ela seu enunciado não faria sentido, não seria interpretável. Ele tem, pois, de se inscrever no repetível" (ORLANDI, 1998, p. 13). Assim, podemos interpretar o conceito apresentado pelo aluno na forma escrita ou oral em sala de aula como uma repetição dos conceitos com os quais ele já teve contato. Ao especificar a repetição, Orlandi a distingue em três formas - empírica, formal e histórica -, que, se considerado o aluno como autor da repetição, podem ser assim entendidas: (a) a repetição empírica é observada quando o aluno faz uma cópia fiel do que encontra escrito nos livros ou do que é falado pelo professor; (b) a repetição formal ocorre quando o autor reconstrói a estrutura gramatical do conceito, sem acrescentar conteúdo; e (c) a repetição histórica é aquela em que o aluno, relacionando o conceito apresentado pelo professor e/ou pelos livros com os seus conhecimentos prévios, constrói um conceito que tem sentido próprio. A repetição histórica é a de nível mais alto na aprendizagem. $\mathrm{Na}$ fala do professor Kelvin, é evidente sua intenção de levar o aluno ao modo de repetição histórica: "quero que... eles [alunos] criem o conceito deles", indicando que encoraja seus alunos a construir com as próprias palavras os conceitos da Física. Ele mostra perceber que, na construção do conhecimento, o indivíduo associa valores preconcebidos aos conceitos que estão sendo estabelecidos.

Entre as respostas à pergunta "Qual a metodologia que possibilitaria maior interesse dos alunos?”, distinguimos três: (a) experimentos, (b) exercícios e (c) jogo de perguntas. Em 
cada resposta, é possível encontrar a justificativa para escolha da metodologia, considerando que: "experimentos" é uma "proposta da criação de situações que discutam com o sujeito aprendiz a apropriação de conhecimentos já existentes para as ciências, mas novos para o sujeito” (LIMA; TEIXEIRA, 2011, p. 6); “exercícios” se interpretam como proposições de questões escritas em nível simples, como a aplicação imediata de fórmulas, até questões em nível mais complexo de dificuldade, as quais exigem interpretação de situações para discerni-las e expressá-las em equações matemáticas; e “jogo de perguntas" são perguntas orais feitas durante a aula, para conduzir os alunos a recorrer aos conhecimentos prévios a fim de responder às perguntas propostas.

No concernente ao interesse dos alunos, um professor de São Luís indicou o "jogo de perguntas" ao longo das aulas como o instrumento metodológico que produz maior efeito, mas a maioria dos professores dessa cidade indicou os "experimentos", aspecto indicado também por todos os professores de Coimbra. As respostas dadas pela maioria dos sujeitos de ambos os grupos valorizaram as possíveis relações construídas nas aulas de Física a partir de situações observadas no dia a dia, de modo que os alunos possam identificar a constante presença de conhecimentos de Física em seu cotidiano.

Os experimentos têm características pedagógicas interessantes, por possibilitarem o estudo da ciência com uma linguagem diferente da linguagem científica encontrada nos livros didáticos. A linguagem científica apresenta dificuldades para os alunos, principalmente para aqueles que dão seus primeiros passos nesse estudo, pois os acontecimentos e os processos são descritos com verbos estabelecidos por processos de nominalização: "a linguagem científica substitui os processos, expressos normalmente por verbos, por grupos nominais” (MORTIMER, 1998, p. 104). Para exemplificar com um fato expresso na linguagem cotidiana e na linguagem científica, Mortimer (1998, p. 103) afirma:

\begin{abstract}
Ao nos referirmos a como o aumento de temperatura afeta a dissolução de sal de cozinha em água no nosso cotidiano, normalmente falamos: quando colocamos sal em água e aquecemos, conseguimos dissolver uma maior quantidade do que em água fria. $\mathrm{Na}$ linguagem científica, expressaríamos esse mesmo fato de uma forma diferente: o aumento de temperatura provoca um aumento da solubilidade do sal.
\end{abstract}

Os experimentos podem facilitar o envolvimento do aluno com a ciência, pois utilizam a linguagem científica em situações dinâmicas, semelhantes aos fenômenos que ele identifica em seu cotidiano. Isso pode justificar o fato de a maioria dos professores de São Luís e todos os de Coimbra afirmarem que o uso de experimento no ensino de Física produz maior interesse dos alunos.

Em resposta à pergunta sobre a metodologia utilizada, três professores de São Luís indicaram o uso de "experimentos" como mais eficaz para a aprendizagem efetiva, e dois afirmaram que, para a melhor aprendizagem, cabe o "jogo de perguntas". Os professores de Coimbra foram unânimes em apontar que, para a aprendizagem efetiva, a preponderância deve incidir sobre a realização de "exercícios", os quais permitem ao aluno aprender com profundidade. A resposta dos portugueses é condizente com a característica do ensino científico, que exercita a habilidade do estudante para resolução de problemas, com a função de alimentar um contínuo retorno aos conceitos apresentados e, assim, garantir o aprendizado. Se considerarmos, ainda, 
que a formação dos professores de Física é marcada pela realização de muitos exercícios, evidenciada pela quantidade deles dispostos no fim de cada capítulo dos livros da bibliografia básica de qualquer disciplina de Física, as respostas dos professores de São Luís parecem surpreender, pois não indicam ser a resolução de exercício a metodologia que proporcione maior aprendizagem.

Uma possível explicação para as respostas dos professores brasileiros - ao entenderem que os alunos têm maior compreensão da ciência quando utilizam "experimentos" ou quando fazem “jogo de perguntas” durante as aulas, e não durante a resolução de exercícios - poderá estar associado ao fato de seus alunos não terem conhecimentos matemáticos suficientes para avançar com uma motivação mínima que permita envolvê-los com a resolução de exercícios. Nesse sentido, Almeida (2012, p. 36) identifica que, nos discursos, tanto do professor formador de formadores quanto do professor do ensino básico, a "grande diferença entre as linguagens comum e matemática pode inibir possíveis intervenções dialógicas dos estudantes que não conhecerem o que está sendo dito em linguagem matemática" e ressalta que em uma pesquisa no Brasil

[...] realizada através de um questionário respondido por aproximadamente 200 estudantes do último ano do Ensino Médio no município de Porto Alegre, sugerem que, para eles, a física é centrada unicamente em cálculos numéricos, sendo que para ser bem sucedido na disciplina é necessário decorar fórmulas (ALMEIDA, 2012, p. 36).

Considerando que, durante a graduação, a formação do professor brasileiro é feita com ênfase na linguagem matemática e os conteúdos de Física não são trabalhados com o objetivo de utilizá-los no Ensino Médio, o professor, ao repetir o que aprendeu em sua formação, ou seja, ao desenvolver a resolução de problemas de física tendo como base a linguagem matemática, leva o aluno do Ensino Básico a se sentir incapaz, por não ter o conhecimento matemático que lhe permita acompanhar esse raciocínio. Em consequência, o aluno perde o interesse pela aula.

As respostas dos professores brasileiros às perguntas "Na prática, como organizaria as aulas, da primeira à última? Como as desenvolveria do começo ao fim?” mostram a intenção de promover aulas expositivas dialogadas, nas quais a aprendizagem se dê pela articulação entre conhecimentos prévios dos alunos e os que serão apresentados, procurando estimular a participação com perguntas e fomentando o debate:

Primeira aula: Tento fazer com que os alunos se identifiquem com o conteído e vejam relação com coisas do dia a dia, por meio de vídeos, leitura, fotos. Aulas intermediárias: Inicio o conteúdo com conceitos, desenhos, experimentos produzidos pelos próprios alunos, mantendo sempre o debate em turma, finalizando com a formulação do conceito físico. Última aula: Resolução de exercícios, do muito fácil ao mais complexo. [Ana].

Primeira aula: Deixo claro o assunto que será trabalhado. Focalizo em uma pergunta para que, durante a aula, estejam em busca da resposta, e, ao finalizar a aula, a pergunta tem que estar respondida. Última aula: Dedico à resolução de exercícios. Se der tempo, os exercícios são feitos na mesma aula da aula de conceito e então finalizo o tema. Os exercícios são numéricos e com conceitos. Dependendo do nível da turma, trabalho com problemas também. [Tânia]. 
Primeira aula: Faço perguntas sobre o dia a dia dos alunos, relacionando com o conteúdo. Exponho o conteúdo, fazendo uma inter-relação com os conceitos anteriores. Última aula: Trabalhamos com alguma atividade que envolva vídeo, CDs de Física e laboratório. [Cássio].

Primeira aula: Inicio fazendo perguntas, interagindo com os alunos. Coloco o conceito físico. Faço a formulação. Depois passamos a resolver exercícios básicos. Última aula: Recapitulo os conceitos anteriores e depois continuamos resolvendo exercícios com um gran mais alto de dificuldade. [Murilo].

Primeira aula: Dedico à construção do conceito por meio de perguntas diretas a respeito do que eles entendem por cada uma das grandezas e onde se aplica. Última aula: Ensino a calcular o trabalho em diversas situações. [Kelvin].

Os professores de São Luís descrevem o início de suas aulas como um momento de investigação sobre os conhecimentos prévios dos alunos, quando, a partir de respostas a duas perguntas, fazem conexões entre o conhecimento prévio e o conteúdo proposto, finalizando com exercícios para fixação e para avaliação da aprendizagem.

Em aulas expositivas dialogadas, a aprendizagem se dá pela articulação entre conhecimentos prévios dos alunos e os que lhes serão apresentados. Nesse contexto, o envolvimento do aluno, expressando o que pensa, é indispensável.

Analisando as respostas dos professores de Coimbra às perguntas "Na prática, como organizaria as aulas, da primeira à última? Como as desenvolveria do começo ao fim?”, não fica evidente que eles alimentam a participação dos alunos em suas aulas, pois parece que usam a exposição, com predominância da fala do professor, com uso do quadro e do silêncio dos alunos. Para a organização das aulas, eles afirmaram:

Primeira aula: Fazer inferências do que os alunos já sabem. Aula intermediária: Resolução de exercícios, exemplos, perguntas. Eventualmente, trabalhos de grupo e/ ou casa e atividade laboratorial. Última aula: um resumo para ver se [os alunos] apreenderam os conteúdos. [Sofia].

Primeira aula: Introduzo o tema com assuntos anteriores. Aula intermediária: dou exemplos concretos e exercícios. Última aula: Dedico à resolução de exercícios e problemas e sintetizo o que foi dado nas aulas para finalizar e passar para o próximo assunto. [Miguel].

Primeira aula: Diferencio a linguagem do cotidiano e a cientifica. Depois apresento o conceito físico e a formulação de trabalho. Última aula: Resolução de exercícios e problemas. [Joana].

Pela descrição dos professores de Coimbra, os conteúdos desenvolvidos em suas aulas são tratados a partir dos conhecimentos que eles acreditam que os alunos trazem, e não a partir de perguntas investigativas que lhe fazem diretamente. Isso condiz com as falas desses 
professores que afirmam registrar os conteúdos, o desenvolvimento das aulas e o desempenho de aprendizagem previsto no planejamento das aulas. Talvez eles se apoiem nesse registro para inferir os conhecimentos prévios dos alunos, o que os leva, como visto em suas falas, mais diretamente aos conteúdos novos desde a primeira aula. A professora Sofia sinaliza investigar dentro da sala de aula os conhecimentos prévios dos alunos, condizendo com o fato de ela utilizar o plano escrito em grupo pelos professores da escola e não realizar por escrito o seu próprio plano.

A análise das respostas dos professores na descrição de suas aulas, da primeira à última, mostra que aqueles que disseram não registrar o plano sentiam a necessidade de fazer perguntas aos alunos na primeira aula para inferir seu conhecimento prévio. Por outro lado, os professores que disseram registrar seus próprios planos - Ana, Tânia, Miguel e Joana - mostraram-se seguros para trabalhar os conteúdos da disciplina desde a primeira aula, o que nos parece ser um indicativo do quanto o registro do plano e do acompanhamento do progresso do aluno auxilia o professor e revela maior domínio sobre os conhecimentos adquiridos pelos alunos.

Esse trabalho, ao buscar compreender como os planos de aulas foram produzidos por professores brasileiros e portugueses, considerou que eles poderiam se constituir em determinadas condições imediatas e sócio-históricas, considerando a história de vida de cada professor que a constitui pela memória. Na perspectiva da AD, o papel da memória é fundamental pela maneira como aciona as condições de produções, ou seja, como aciona os sujeitos e as situações (ORLANDI, 2009), onde consideramos os professores brasileiros e portugueses como sujeitos e os espaços/posições de formação e de atuação profissional as situações que interferem e determinam o planejamento de suas aulas.

\section{Considerações finais}

As experiências estabelecidas nos discursos de cada professor, nos levou a interpretar aspectos da constituição do planejamento de suas aulas, mas, como entendido pela $\mathrm{AD}$, sem a pretensão de buscar neles um sentido verdadeiro, sentido único ou sentido oculto (ORLANDI, 2004, 2009).

Nos discursos dos profissionais portugueses e brasileiros, os conhecimentos prévios dos alunos são valorizados no processo de elaboração de planos de aulas, pelos portugueses com ênfase na intenção de mediar conteúdos em sala de aula e pelos brasileiros associados inicialmente a situações do dia a dia para mostrar a importância de se estudar a Física.

No contexto brasileiro, identificamos discursos com tendências de valorização de práticas cuja intenção é "construir" conhecimento mediante a interação entre o professor e o aluno, como mostrado nas falas: "quero que primeiro eles [alunos] criem o conceito deles" [Kelvin] e "fico atenta para saber se eles entenderam o que é uma força. Observo se eles aprenderam os assuntos anteriores necessários para dar continuidade ao conteúdo" [Tânia]. Em situação de aula, Ana revela: "inicio o conteúdo com conceitos, desenhos, experimentos produzidos pelos próprios alunos, mantendo sempre o debate em turma, finalizando com a formulação do conceito físico", como indicativo de ênfase na apropriação e interiorização do conhecimento pelos alunos.

No âmbito das escolas portuguesas, os três professores indicam tendências de ensino mais expositivo, sem uma manifesta preocupação com o trabalho de "construção" do conhe- 
cimento na interação com os alunos. Joana, ao pensar no planejamento das aulas, lembra o que pretende ensinar para não se esquecer de "resgatar o conbecimento dos alunos", enquanto Miguel "não espera que os alunos cheguem ao conceito de forma intuitiva". Em situação de aula, a resolução de exercícios e problemas fazem parte do planejamento, tanto de Miguel como de Joana, mostrando tendência para prática de padronizações de avaliações valorizadas pelo ensino mais tradicional.

Em relação às considerações feitas, observamos que os discursos dos professores portugueses e brasileiros manifestam tendências ao uso de referenciais metodológicos de ensino, sem restrições a possibilidades de diferentes abordagens pedagógicas, buscando adaptá-las às condições de ensino que se apresentam.

\section{Agradecimento}

As duas primeiras autoras agradecem o suporte financeiro concedido pela Coordenação de Aperfeiçoamento de Pessoal de Nível Superior (Capes) que possibilitou a realização deste trabalho.

\section{Referências}

ALMEIDA, M. J. P. M. Discurso pedagógico e formação de professores de ciências da natureza: foco no professor de física. Alexandria, Florianópolis, v. 5, n. 2, p. 29-41, 2012. Disponível em: <https://periodicos.ufsc.br/index.php/alexandria/article/view/37712>. Acesso em: 3 out. 2018.

CAMACHO, T. A universidade pública no Brasil. Revista de Sociología, Santiago de Chile, n. 19, p. 100-133, 2005. Disponível em: < https://revistadesociologia.uchile.cl/index.php/ RDS/article/view/27816/29484>. Acesso em: 2 fev. 2015.

DAMIÃO, M. H. et al. Reorganização curricular de Bolonha: percepções de alunos universitários. In: CONFERÊNCIA O FUTURO DE BOLONHA, 10 ANOS DEPOIS, 2009, Lisboa. Actas... Disponível em: < https://aepq.tecnico.ulisboa.pt/files/sites/22/ FCG_bolonha_10_anos_depois.pdf>. Acesso em: 2 fev. 2015.

FÁVERO, M. L. A. A universidade no Brasil: das origens à reforma universitária de 1968. Educar em Revista, Curitiba, v. 22, n. 28, p. 17-36, 2006. Disponível em: < https://revistas. ufpr.br/educar/article/view/7609/5423>. Acesso em: 2 fev. 2015.

GAGNÉ, R. M. Princípios essenciais da aprendizagem para o ensino. Porto Alegre: Globo, 1980.

INEP. Sinopse estatística da educação básica: 2013. Brasília, 2013. Disponível em: $<$ http://portal.inep.gov.br/web/guest/sinopses-estatisticas-da-educacao-basica $>$. Acesso em: 2 out. 2018. 
LIMA, K. E. C.; TEIXEIRA, F. M. A epistemologia e a história do conceito experimento/ experimentação e seu uso em artigos científicos sobre ensino das ciências. In: ENCONTRO NACIONAL DE PESQUISA EM EDUCAÇÃO EM CIÊNCIA, 8., 2011, Campinas.

Atas... Disponível em: <http://www.nutes.ufrj.br/abrapec/viiienpec/resumos/R0355-1. pdf $>$. Acesso em: 12 jun. 2014.

LUCKESI, C. C. Filosofia da educação. 3. ed. São Paulo: Cortez, 2011.

MARANHÃO. Ministério Público. Análise situacional das escolas municipais de São Luís. São Luís: Procuradoria Geral de Justiça, 2010.

MORTIMER, E. F. Sobre chamas e cristais: a linguagem cotidiana, a linguagem científica e o ensino de ciências. In: CHASSOT, A.; OLIVEIRA, R. J. (Org.). Ciência, ética e cultura na educação. São Leopoldo: UNISINOS, 1998. p. 99-118.

OECD. Education at a glance 2014: OECD indicators. Paris, 2014. Disponível em: <https://doi.org/10.1787/eag-2014-en>. Acesso em: 12 fev. 2015.

ORLANDI, E. P. Análise de discurso: princípios e procedimento. Campinas: Pontes, 2009.

ORLANDI, E. P. Discurso, imaginário social e conhecimento. Em Aberto, Brasília, v. 14, n. 61, p. 53-59, 1994. Disponível em: < http://emaberto.inep.gov.br/index.php/emaberto/ article/view/1943/1912>. Acesso em: 3 out. 2018.

ORLANDI, E. P. Interpretação: autoria, leitura e efeitos do trabalho simbólico. Campinas: Pontes, 2004.

ORLANDI, E. P. Michel Pêcheux e a análise de discurso. Estudos da Língua(gem), Vitória da Conquista, n. 1, p. 9-13, 2005. Disponível em: <http://www.estudosdalinguagem. org/index.php/estudosdalinguagem/article/viewFile/4/3>. Acesso em: 3 out. 2018.

ORLANDI, E. P. Paráfrase e polissemia: a fluidez nos limites do simbólico. Rua, Campinas, v. 4, n. 1, p. 9-19, 1998. Disponível em: <https://periodicos.sbu.unicamp.br/ojs/index.php/ rua/article/view/8640626/8177>. Acesso em: 3 out. 2018.

PORDATA: Base de Dados Portugal Contemporâneo. Educação: alunos do ensino não superior. Fundação Francisco Manuel dos Santos, 2013. Disponível em: <http:/ /www. pordata.pt/Subtema/Portugal/Alunos + do + Ensino+Nao+Superior-75>. Acesso em: 18 fev. 2015.

PORTUGAL. Instituto Nacional de Estatística. Estatísticas demográficas 2011. Lisboa: Instituto Nacional de Estatística, 2013 a.

PORTUGAL. Ministério da Educação e Ciência. Avaliação externa das escolas 20112012: relatório. [Lisboa], 2013b. Disponível em: <http://sdpsul.com/2/wp-content/ uploads/2013/04/AEE_2011-2012_RELATORIO.pdf>. Acesso em: 14 maio 2015.

RICARDO, E. C.; FREIRE, J. C. A. A concepção dos alunos sobre a física do ensino médio: um estudo exploratório. Revista Brasileira de Ensino de Física, São Paulo, v. 29, n. 2 , p. 251-266, 2007. Disponível em: <https://doi.org/10.1590/S1806-11172007000200010>. Acesso em: 3 out. 2018. 
Lima, M. C. A.; Lima, R. M. S.; Damião, M. H.

SEIXAS, A. M. et al. A formação inicial de professores nas universidades portuguesas: da reforma dos anos 70 às repercussões do processo de Bolonha. In: MELO, M. A.; NASCIMENTO, I. V. (Org.). Licenciaturas: métodos e práticas em diálogo. São Luís: EdfMa, 2012. p. 137-150.

Artigo recebido em 07/09/2016. Aceito em 18/05/2018.

Contato: Universidade Federal do Maranhão, Departamento de Física, Avenida dos Portugueses, 1966, São Luís, MA, 65080-805, Brasil. 